\title{
Modeling and development of a decision support system for supplier selection in the process industry
}

\author{
Pandian Pitchipoo ${ }^{1 *}$, Ponnusamy Venkumar ${ }^{2 \dagger}$ and Sivaprakasam Rajakarunakaran ${ }^{2 \dagger}$
}

\begin{abstract}
This paper presents the development of a model based decision support system with a case study on solving the supplier selection problem in a chemical processing industry. For the evaluation and selection of supplier, the analytical hierarchy process (AHP) and grey relational analysis (GRA) were used. The intention of the study is to propose an appropriate platform for process industries in selecting suppliers, which was tested with an electroplating industry during the course of development. The sensitivity analysis was performed in order to improve the robustness of the results with regard to the relative importance of the evaluation criteria and the parameters of the evaluation process. Finally, a practical implementation study was carried out to reveal the procedure of the proposed system and identify the suitable supplier with detailed discussions about the benefits and limitations.
\end{abstract}

Keywords: Supplier evaluation; Supplier selection; Model base; Decision support system; Analytical hierarchy process; Grey relational analysis

\section{Background}

Supplier selection is one of a critical decision in supply chain management in both manufacturing and process industries. In these industries the purchase department often plays an important role in reducing the purchasing cost and selecting appropriate suppliers. Improper evaluation and selection of potential supplier can reduce the organization's supply chain performance. Besides, supplier selection process is a multi-criteria decision making problem, in which both qualitative and quantitative factors are included. Because of the complexity and importance of supplier selection decisions, decision support systems (DSS) are generally used for decision-making. An effective DSS has the following components such as inputs [factors, numbers, and characteristics to analyze], user knowledge and expertise [inputs requiring manual analysis by the user], outputs [transformed data from which DSS "decisions" are generated] and decisions [results generated

\footnotetext{
* Correspondence: drpitchipoo@gmail.com

${ }^{\dagger}$ Equal contributors

'Department of Mechanical Engineering, P.S.R. Engineering College, Sivakasi626140, Tamil Nadu, India

Full list of author information is available at the end of the article
}

by the DSS based on user criteria] (Turban et al., 2004). In this paper the development of a model based DSS is discussed with a case study.

The rest of the paper is organized as follows: Literature review section illustrates the review of the relevant literatures in this area and also describes the problem context, Decision support system section, the steps and details of the proposed decision support system integrating AHP, GRA and Hybrid model for supplier selection. In Case study section, an actual application of the proposed method is presented. Systems integration and implementation section, System integration and implementation are explained. Finally, Conclusion section concludes the study and outlines some future research directions.

\section{Literature review}

The literature review is categorized into outline of supplier evaluation and selection, overview of models and decision support system applications.

\section{Outline of supplier evaluation and selection}

The identification of influencing criteria for the evaluation and selection of suppliers was focused by many researchers. 
Dickson (1966) carried out a study by the help of a survey which was conducted in 300 business organizations. The purchasing managers of those organizations were requested to identify the factors that were influencing the supplier selection. As an outcome of the survey, totally 23 factors were identified as important factors for the supplier selection decision problem. Weber et al. (1991) reviewed a total of 74 research papers on supplier selection and identified net price (cost), delivery, quality, production capability, geographical location, technical capability, reputation, financial position, performance history and warranty are the most contributed criteria for supplier selection. Boer et al. (2001) presented a review of decision methods based on an extensive search in the academic literature for the supplier selection process. Ho et al. (2010) reviewed the literatures related to the multi-criteria decision making approaches for supplier evaluation and selection appearing in the international journals from the year 2000 to 2008 . For the supplier selection various techniques such as mathematical programming (linear programming, integer programming and goal programming), data envelopment analysis, AHP, analytical networking process, fuzzy set theory, and genetic algorithm were found in literatures. In most of the literatures, quality, delivery and price/cost were considered as the most influencing criteria for supplier evaluation and selection.

\section{Overview of models}

In this section, the relevant literatures to the proposed models such as GRA, AHP and hybrid AHP-GRA were reviewed.

\section{Grey relational analysis (GRA) applications}

Deng (1989) introduced the Grey theory that provides an effective means to solve problems containing uncertainty and indetermination. It was suitable to the decision-making under more uncertain environments. Tsai et al. (2003) have developed a supplier selection model for a garment industry using grey relational analysis. For this work the quality of the product, price, delivery date, quantity and services were considered to evaluate the suppliers. Hsu et al. (2008) evaluated the competencies of various suppliers of a centrifugal pump manufacturer in Taiwan using GRA. Li et al. (2008) proposed the grey rough set theory approach for supplier selection. In that approach the linguistic variable assigned to the alternatives were converted into grey number. The most suitable supplier was determined by GRA based on grey number. Tseng (2010) proposed GRA approach to deal with supplier evaluation of environmental knowledge management capacities with uncertainty and lack of information.

\section{Analytical hierarchy process (AHP) applications}

Narasimahn (1983) suggested the use of the AHP approach for vendor selection problems. Kumar and Parashar
(Kumar et al. 2009) applied analytical hierarchy process (AHP) for vendor selection process with the evaluation of multiple criteria and various constraints associated with small, medium and large scale industries. Chakraborty et al. (2005) evaluated the performance of existing die casting vendors of a light engineering industry using AHP tool. Cebi and Bayraktar (2005) solved the supplier selection problem for a food processing industry considering the qualitative and quantitative factors by using AHP and lexicographic goal programming (LGP) integrated model. Water and Peet (2006) presented a decision making model for taking make or buy decision using AHP for a shipyard in the Netherlands. Chan et al. (2007) developed an AHP based decision making approach to solve the supplier selection problem. Potential suppliers were evaluated and a sensitivity analysis using expert choice was performed to examine the responses of various alternatives. Tahriri et al. (2008) developed an AHP-based supplier selection model and applied to a real case study for a steel manufacturing company in Malaysia. Pitchipoo et al. (2011) developed an AHP model for the evaluation and selection of supplier for an electroplating industry in India.

\section{Hybrid approach applications}

Yang and Chen (2006) proposed an integrated model by combining AHP and GRA to evaluate and select the supplier for a notebook computer manufacturer. In this study an integrated model was formulated to examine the feasibility in selecting a best supplier and the effectiveness of the integrated model was demonstrated. Haq and Kannan (2006) proposed an integrated model comprising of AHP and GRA for the evaluation and selection of vendor in a forward supply chain. Pitchipoo et al. (2012) constructed an Excel based DSS for supplier selection process by integrating the AHP and GRA. First the highly influencing criteria were selected using Shannon mutual information based feature selection method and then the weights of the selected criteria were calculated using AHP. Finally the best supplier was selected using GRA.

\section{Decision support system (DSS) applications}

Son (1991) developed a decision support system for the automation of the processes in a factory. The cost effectiveness of the DSS was justified with the help of a case study conducted in a manufacturing firm. Chan (2003) suggested an interactive supplier selection model using AHP. The DSS was developed with the help of the multi-criterion decision making software called Expert Choice. Snijders et al. (2003) developed an electronic DSS to help the procurement managers and also compare the human decision with the decision made by the DSS. Moynihan (2006) developed a decision support system for procurement operations, which focuses primarily on procurement operations within a manufacturing environment. Hou and Su (2007) 
developed an AHP based decision support system for the supplier selection problem in a mass customization environment. Gerardo (2007) proposed an alternative decision support system using Visual Interactive Goal Programming (VIG) for supplier selection problem.

Kumar and Rajender Singh (2008) developed a rulebased expert system for selection of piloting to assist die designers and process planners working in stamping industries. Montazer et al. (2009) developed an expert decision support system (EDSS) using a fuzzy version of ELECTRE III method for ranking the alternatives based on the experts' knowledge. This EDSS was applied to a vendor selection process in an Iranian oil industry. Razmi et al. (2009) developed a fuzzy analytic network process (ANP) model based DSS to evaluate the potential suppliers and select the best. Elanchezhian et al. (2010) proposed AHP for the selection of supplier for the glass product manufacturing industry. This software package was developed to meet the requirement of the purchase manager in the purchase of raw material. Kumar et al. (2011) developed a DSS for supplier selection based on fuzzy decision making techniques. The DSS was developed for a metal fabrication industry. Miah and Huth (2011) demonstrated a decision support system for supplier selection using multi attribute utility approach. The application of the approach was demonstrated using a subset of sample data from a real-world project.

\section{Decision support system}

Developing a decision support system for supplier selection is to assist the decision makers to obtain quick and accurate actions. In an organization, the decision support system was built to reduce the risk faced by procurement department because the procurement is a profit-contributing activity instead of a routine order-placing function (Moynihan, 2006). However, the absence of an adequate support system to assist the decision maker which results in inefficient and ineffective procurement may affect the profitability of the entire organization.

\section{Proposed DSS framework}

DSS is an interactive computer based system which helps the decision makers to utilize the data and models to solve large and complex decision problems. The framework of the proposed DSS is depicted in Figure 1. This system aims to develop appropriate decision strategies for supplier evaluation and selection in a process industry.

The proposed DSS contains of the following three components:

- Database system: It is enhancing the availability and access of various data necessary for model development in an accurate and precise manner.

- Model base system: This subsystem contains three supplier evaluation and selection models namely AHP model, GRA model and hybrid model with a sensitivity analysis model for testing the robustness of results.

- User interface system: Interact directly with a decision maker or a participant in the decision making process in such a way that the user has a flexible choice and sequence of selection strategies.

The proposed DSS can be used by the decision makers for the selection of suitable suppliers with appropriate

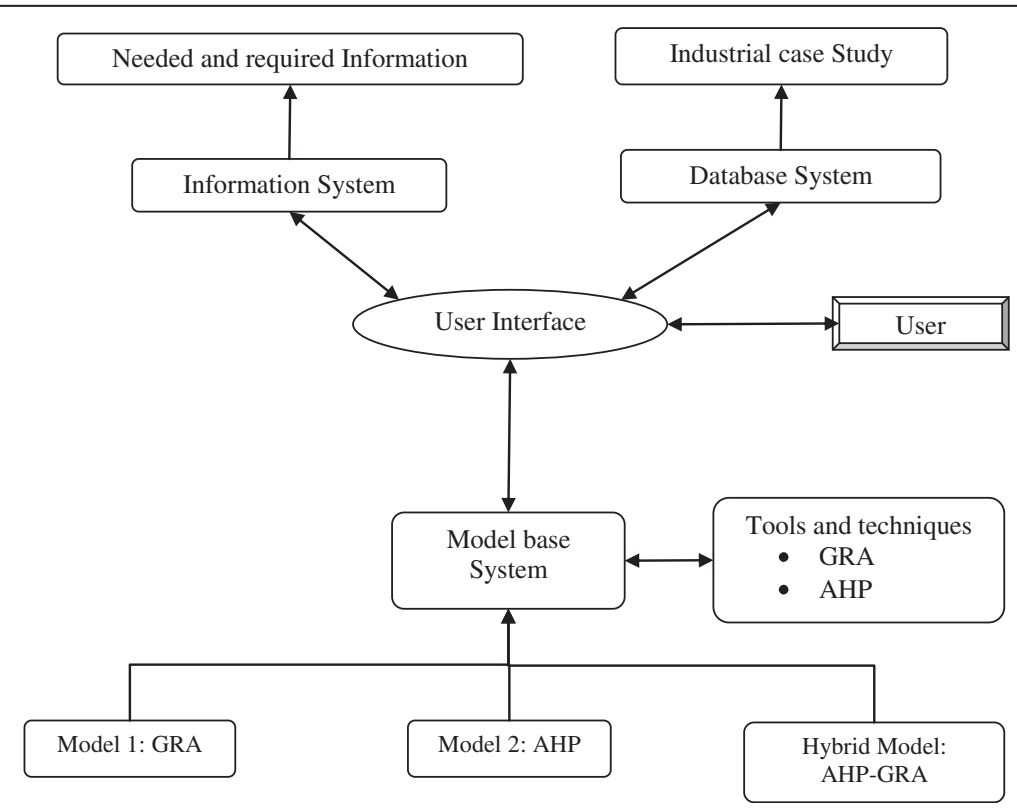

Figure 1 Framework of the proposed decision support system for supplier selection. 
evaluation strategies. It will help them to make strategic decisions in the purchase activity where the risks are involved in the selection of suitable suppliers to be tackled and in deciding which procurement limitations are to be resolved. The proposed DSS will be tested and validated with sample data collected from electroplating industry in Case study section.

\section{Database management system (DBMS)}

A database is an integrated collection of data records, files, and other data related to the decision problem. It allows organizations to conveniently develop databases for supplier selection, which typically supports the needed query language and dedicated database language. The proposed DBMS provides facilities for creation, controlling data access, enforcing data integrity, recovering the database after failures and restoring it from backup files, maintaining database security with updation and report generation options (Lee et al. 2006).

To enhance the data quality and avoid data redundancy, it is necessary to develop DBMS with data extracted from the internal sources such as finance, production and procurement departments and external sources including journals, reference books, websites and materials from similar industries. The data categories in this study that are relevant to supplier evaluation and selection can be defined as quantitative criteria (cost of the material and delivery lead time) and qualitative criteria (quality of the supplied materials, warranty given on the material by the supplier and production capacity of the suppliers). The theoretical information related to the organization such as organization structure, raw materials, products, processes and the details about the tools used for the evaluation of the suppliers were included as help menu of DSS. It helps the users to know about the organization and tools which are used for this study.

\section{Model base management system (MBMS)}

The model base in a DSS gives decision makers access to a variety of models which are developed for this specific application to assist the decision makers in the decision making process. These models mathematically represent

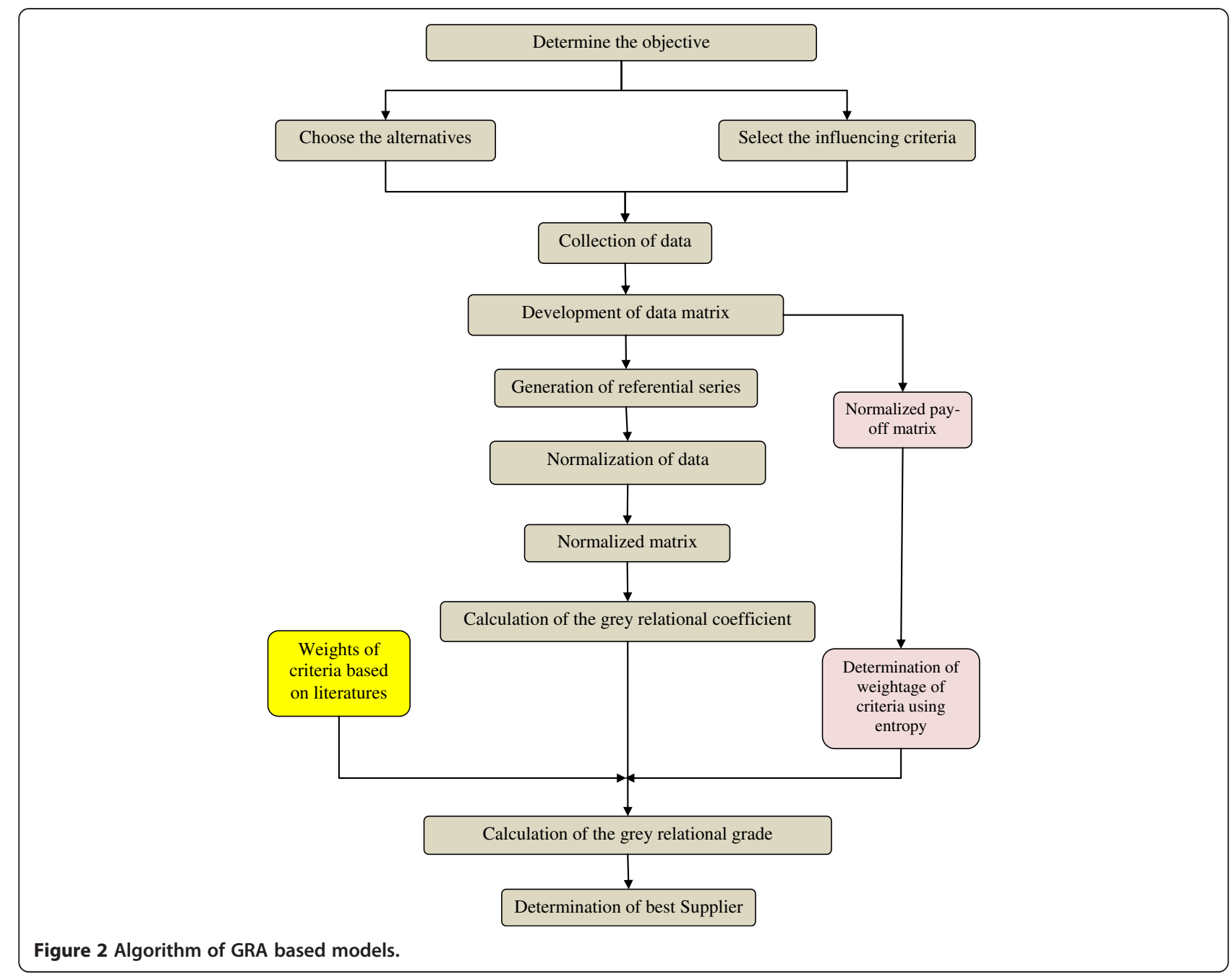




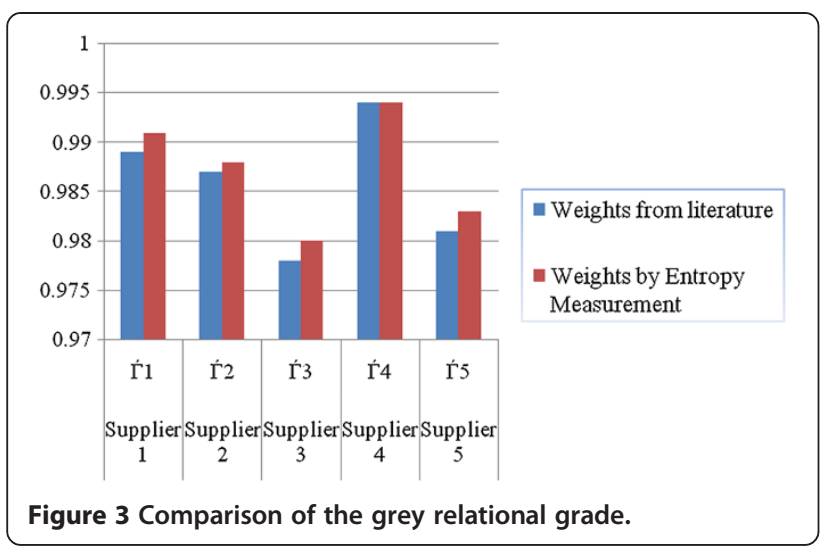

the various decision making activities and provide necessary decision support based on built in analytical tools which are used in this proposed DSS namely, AHP and GRA. Generally the model formulation process plays a major role in the result of the decision-making process. The purpose of the MBMS is to transform data from the DBMS into information that is useful in decision making. The developed model base management system has the facilities such as model base, model directory, model execution, integration of models and command processor. The model directory for this specific application consists of the following:

- GRA model in which the evaluation was done based on quantitative criteria.

- AHP model which is used to evaluate the suppliers based on both qualitative and quantitative criteria.

- Hybrid model which is developed to use the advantages of both AHP and GRA.

The important functions of the MBMS allow the users to manipulate models so that they can conduct experiments and sensitivity analysis from what - if to goal seeking (Ma et al. 2010). It also stores, retrieves and manages a

Table 1 Criteria matrix and normalized matrix for GRA model

\begin{tabular}{cccccc}
\hline & Suppliers & $\begin{array}{c}\text { Cost } \\
\text { (Rs) }\end{array}$ & $\begin{array}{c}\text { Delivery } \\
\text { (Days) }\end{array}$ & $\begin{array}{c}\text { Capacity } \\
\text { (Units) }\end{array}$ & $\begin{array}{c}\text { Warranty } \\
\text { (days) }\end{array}$ \\
\hline Criteria matrix & Supplier 1 & 2439 & 12 & 170 & 28 \\
& Supplier 2 & 2567 & 12 & 260 & 21 \\
& Supplier 3 & 2711 & 14 & 280 & 21 \\
& Supplier 4 & 3099 & 10 & 260 & 14 \\
& Supplier 5 & 2302 & 13 & 290 & 18 \\
Normalize matrix & Supplier 1 & 0.828 & 0.500 & 0.000 & 1.000 \\
& Supplier 2 & 0.668 & 0.500 & 0.750 & 0.500 \\
& Supplier 3 & 0.487 & 0.000 & 0.917 & 0.500 \\
& Supplier 4 & 0.000 & 1.000 & 0.750 & 0.000 \\
& Supplier 5 & 1.000 & 0.250 & 1.000 & 0.286 \\
\hline
\end{tabular}

Table 2 Grey relational coefficient

\begin{tabular}{lccccc}
\hline Suppliers & $\begin{array}{c}\text { Grey } \\
\text { relational } \\
\text { coefficient }\end{array}$ & Cost & Delivery & Capacity & Warranty \\
\hline Supplier 1 & $\gamma_{1}$ & 0.99995027 & 0.966 & 0.998 & 1.000 \\
Supplier 2 & $\gamma_{2}$ & 0.99990381 & 0.966 & 0.999 & 0.988 \\
Supplier 3 & $\gamma_{3}$ & 0.99985134 & 0.933 & 1.000 & 0.988 \\
Supplier 4 & $\gamma_{4}$ & 0.99971035 & 1.000 & 0.999 & 0.976 \\
Supplier 5 & $\gamma_{5}$ & 1.00000000 & 0.949 & 1.000 & 0.983 \\
\hline
\end{tabular}

wide variety of different types of models in an integrated manner.

\section{User system interface and hardware}

The hardware needed for this DSS includes input data entry devices, central processing unit, data storage files and output devices. Input data entry devices allow entering, verifying, and updating the required data. The central processing unit (CPU) is the core part to control the other computer system components. Data storage files are the saved useful information, and this part also helps the decision maker to search past history easily. Output devices provide a visual or permanent record for the decision maker to store or read. This output device refers to the visual output device such as monitor or printer.

A DSS needs to be efficient to retrieve relevant data for decision makers, so the user system interface is very important. It is crucial that the interface must fit the decision maker's decision-making style (O'Brien and Marakas, 2004). If the decision maker is not comfortable with the user system interface the purpose of DSS will not be attained. The interfaces available in this developed DSS are scheduled reports, questions/answers and menu driven input/output.

\section{Results and Discussion}

The developed DSS is tested with the case study in an Electroplating industry to select the best supplier for its raw materials. The nature of electroplating industry selected for this study is involved in nickel coating and chrome plating for auto components. Moreover this type of industries is highly hazardous in nature and these industries are operating as small factories and workshops. At present the supplier selection is done based on bidding technique. In this current practice, the quality and supply lead time were not considered. But

\section{Table 3 Relative weights of criteria}

\begin{tabular}{ccccc}
\hline & Cost & Delivery & Capacity & Warranty \\
\hline $\begin{array}{c}\text { Weights of criteria from } \\
\text { literature (Cheraghi, 2004) }\end{array}$ & 0.2337 & 0.2896 & 0.2352 & 0.2415 \\
$\begin{array}{l}\text { Weights of criteria by using } \\
\text { entropy measurement }\end{array}$ & 0.2445 & 0.2450 & 0.2518 & 0.2587 \\
\hline
\end{tabular}


Table 4 Grey relational grade

\begin{tabular}{llcc}
\hline Suppliers & \multicolumn{2}{c}{ Grey relational grade } \\
\cline { 2 - 4 } & & $\begin{array}{c}\text { Weights of criteria } \\
\text { from literature }\end{array}$ & $\begin{array}{c}\text { Weights of criteria by using } \\
\text { entropy measurement }\end{array}$ \\
\hline Supplier 1 & $\Gamma_{1}$ & 0.989 & 0.991 \\
Supplier 2 & $r_{2}$ & 0.987 & 0.988 \\
Supplier 3 & $r_{3}$ & 0.978 & 0.980 \\
Supplier 4 & $r_{4}$ & 0.994 & 0.994 \\
Supplier 5 & $\Gamma_{5}$ & 0.981 & 0.983 \\
\hline
\end{tabular}

these industries have to ensure that their product must meet the international standards and quality requirements to remain competent in the market. To achieve this, it is a necessary requirement that the supply of raw material or any other kind of necessary inputs should be selected appropriately. For this study the evaluation of suppliers is carried out based on the criteria such as performance assessment criteria, manufacturing criteria, quality system assessment criteria and business factors.

\section{Model 1: GRA base models}

Grey system theory was proposed by Deng (1989) and it is a mathematical theory that was born by the concept of grey set. It is one of the effective methods that are used to solve uncertainty problems under discrete data and partial information. The grey relation is the relation with incomplete information. GRA is an important approach of grey system theory in the application of estimating a set of alternatives in terms of decision attributes. The major advantage of grey theory is that it is suitable to handle both incomplete information and unclear problems. For the development of GRA based model, the following criteria such as performance assessment criteria (delivery lead time and cost of the material), manufacturing criteria (production capacity of the suppliers) and quality system assessment criteria (warranty given on the material by the supplier) are considered. The algorithm used for the evaluation and selection process for GRA based models involve the following steps which are shown in Figure 2.

- Step 1: generation of referential series: The evaluation criteria for the available alternatives were tabulated and this was known as criteria matrix (Table 1). The referential series is the optimal values for each criterion from the criteria matrix.

- Step 2: normalization of data set: The criteria matrix was normalized using two approaches: For criteria if the larger value is better (warranty and capacity), the matrix can be normalized using larger the better concept using equation (1), while for a criteria if the smaller value is better (cost and delivery), the matrix can be normalized using smaller the better concept using equation (2). The normalized matrix is shown in Table 1.

$$
\begin{aligned}
X_{i}^{*}(j) & =\frac{x_{i}(j)-\min x_{i}(j)}{\max x_{i}(j)-\min x_{i}(j)} \\
X_{i}^{*}(j) & =\frac{\max x_{i}(j)-x_{i}(j)}{\max x_{i}(j)-\min x_{i}(j)}
\end{aligned}
$$

where, $\mathrm{i}=1,2, \ldots \mathrm{m}$ (Alternatives); $\mathrm{j}=1,2 \ldots \mathrm{n}$ (Criteria).

Then the absolute difference was calculated between the normalized cell value and the corresponding referential series value by using equation (3). Absolute difference

$$
\Delta_{i}(j)=\operatorname{abs}\left(X_{o}^{*}(j)-X_{i}^{*}(j)\right)
$$

where $X_{o}^{*}(j)=$ referential series value of $\mathrm{j}^{\text {th }}$ criteria; $X_{i}^{* *}(j)=$ normalized cell value of $j^{\text {th }}$ criteria

- Step 3: calculation of the grey relational coefficient: Grey relational coefficient is calculated to express

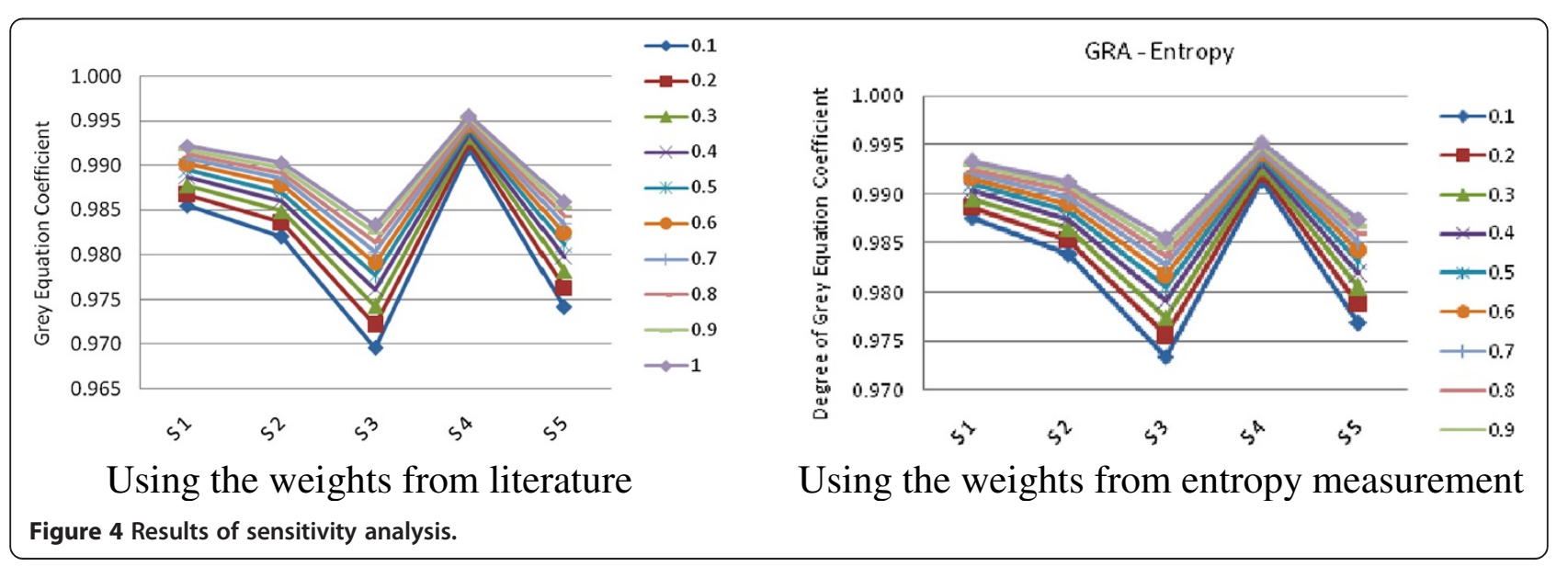




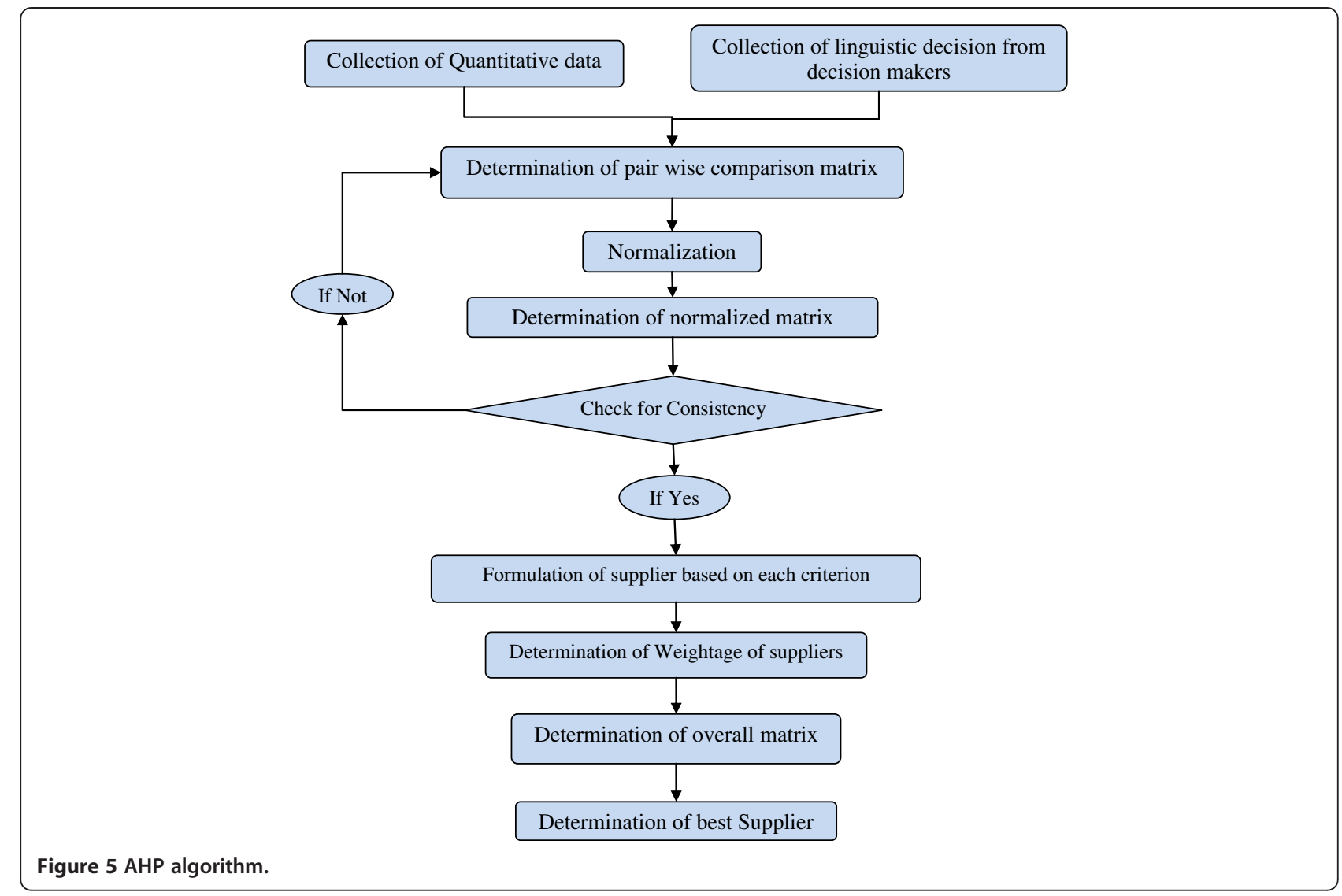

the relationship between the best and the actual results, by using the following equation (4). The grey relational coefficient is given in Table 2 .

$$
\gamma_{i}(j)=\frac{\Delta \min +\xi \Delta \max }{\Delta_{i}(j)+\xi \Delta \max }
$$

where, $\Delta \min =\min _{i} \min _{j} \Delta_{i}(j) ; \Delta \max =\max _{i} \max _{j}$ $\Delta_{\mathrm{i}}(\mathrm{j})$ and $\xi=$ distinguished coefficient $\xi \varepsilon[0,1]$

- Step 4: calculation of the grey relational grade (GRG): The grey relational grade / grey relational grade is calculated using the equation (5).

$$
\hat{\Gamma}_{\mathrm{i}}=\sum_{\mathrm{j}=1}^{3}\left[W_{\mathrm{i}}(\mathrm{j}) \times \gamma_{\mathrm{i}}(\mathrm{j})\right]
$$

where $W_{i}(j)=$ weightage of criteria $j$.

In this work the weights of the criteria were taken from the previous literature (Cheraghi, 2004) and by using entropy measurement approach. The relative weights of criteria are shown in Table 3. In the entropy measurement approach, the weights of criteria were determined using the following steps (Aomar, 2002):

\begin{tabular}{|c|c|c|c|c|c|c|c|}
\hline & Cost & Quality & Delivery & Warranty & Capacity & Reputation & Fin. Posi. \\
\hline Cost & 1 & 0.333 & 3 & 5 & 4 & 6 & 5 \\
\hline Quality & 3 & 1 & 5 & 6 & 7 & 6 & 7 \\
\hline Delivery & 0.333 & 0.2 & 1 & 3 & 4 & 5 & 4 \\
\hline Warranty & 0.2 & 0.167 & 0.333 & 1 & 2 & 3 & 4 \\
\hline Capacity & 0.25 & 0.143 & 0.25 & 0.5 & 1 & 3 & 3 \\
\hline Reputation & 0.167 & 0.167 & 0.2 & 0.333 & 0.333 & 1 & 2 \\
\hline Fin. Posi & 0.2 & 0.143 & 0.25 & 0.25 & 0.333 & 0.5 & 1 \\
\hline Total & 5.15 & 2.153 & 10.033 & 16.083 & 18.666 & 24.5 & 26 \\
\hline
\end{tabular}

Table 5 Criteria matrix - original matrix 
Table 6 Measurement scale for pairwise comparison

\begin{tabular}{lc}
\hline Verbal judgment & Numerical rating \\
\hline Extremely preferred & 9 \\
Very strongly to extremely preferred & 8 \\
Very strongly preferred & 7 \\
Strongly to very strongly preferred & 6 \\
Strongly preferred & 5 \\
Moderately to strongly preferred & 4 \\
Moderately preferred & 3 \\
Equally to moderately preferred & 2 \\
Equally preferred & 1
\end{tabular}

- Formulation of normalized pay-off matrix $\left(\mathrm{P}_{\mathrm{ij}}\right)$ : The criteria matrix (Table 1 ) was normalized using the equation (6). This is called normalized pay-off matrix $\left(\mathrm{P}_{\mathrm{ij}}\right)$.

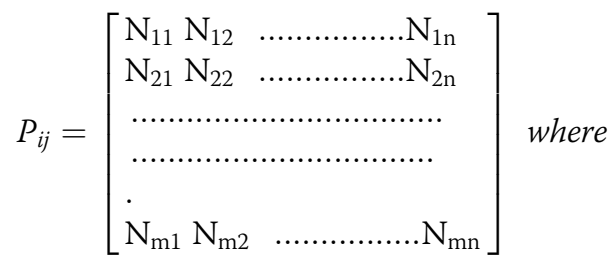

$$
\begin{aligned}
& N_{i j}=\frac{X_{i j}}{\sum_{i=1}^{m} X_{i j}}
\end{aligned}
$$

where, $x_{i}(j)=\mathrm{j}^{\text {th }}$ criteria value for $\mathrm{i}^{\text {th }}$ alternative

- Determination of entropy: The entropy $E_{j}$ of the set of alternatives for criterion $j$ from the normalized pay-off matrix $\left(P_{i j}\right)$ is determined by using the equation (7).

$$
E_{j}=\frac{1}{\ln (m)} \sum_{i=1}^{m} p_{i j} \ln \left(p_{i j}\right)
$$

where, ' $m$ ' is the number of alternatives.

- Determination of degree of diversification: Next the degree of diversification of the information provided by the outcomes of the criterion $j$ is determined using the equation (8).
Table 8 Random indices

\begin{tabular}{ccccccccccc}
\hline $\mathrm{m}$ & 1 & 2 & 3 & 4 & 5 & 6 & 7 & 8 & 9 & 10 \\
\hline $\mathrm{Rl}$ & 0 & 0 & 0.58 & 0.90 & 1.12 & 1.24 & 1.32 & 1.41 & 1.45 & 1.49 \\
\hline & & & & & & & & & \\
& & & & & & & & & \\
& $D_{j}=1-E_{j}$
\end{tabular}

- Determination of weights of criteria: Finally the weights of each criterion were calculated by the following equation (9).

$$
W_{i}(j)=\frac{D_{j}}{\sum_{j=1}^{n} D_{j}}
$$

From the grey relational grade, the supplier with larger coefficient was selected as the best supplier. The priority of the five suppliers was supplier $4>$ supplier $1>$ supplier $2>$ supplier $5>$ supplier 3 . From GRA model application, supplier 4 will be declared as the best supplier. Figure 3 depicts the comparison of the grey relational grade. Table 4 shows the grey relational grade computed by using two different weights.

\section{Sensitivity analysis}

Sensitivity analysis is a technique used to determine how different values of an independent variable will impact a particular dependent variable under a given set of assumptions. It is a method to predict the outcome of a decision if a situation turns out to be different compared to the key predictions. In this sub division, sensitivity analysis for the above said GRA models have been carried out to observe whether the optimal setting is sensitive to the individual response weightages.

That means, if there is any change in optimal setting due to change in relative weightages of the responses; it can be concluded that the optimal setting is sensitive to the individual weightage values. Different weightages [0.1 to 1.0] have been assigned to distinguished coefficient and the results of sensitivity analysis have been presented in Figure 4. Based on the outcome of the

Table 7 Adjusted matrix (normalized matrix)

\begin{tabular}{lcccccccc}
\hline & Cost & Quality & Delivery & Warranty & Capacity & Reputation & Fin. posi & Weights \\
\hline Cost & 0.194 & 0.155 & 0.299 & 0.311 & 0.214 & 0.245 & 0.192 & 0.230 \\
Quality & 0.583 & 0.464 & 0.498 & 0.373 & 0.375 & 0.245 & 0.269 & 0.401 \\
Delivery & 0.065 & 0.093 & 0.100 & 0.187 & 0.214 & 0.204 & 0.154 & 0.145 \\
Warranty & 0.039 & 0.078 & 0.033 & 0.062 & 0.107 & 0.122 & 0.154 & 0.085 \\
Capacity & 0.049 & 0.066 & 0.025 & 0.031 & 0.054 & 0.122 & 0.115 & 0.066 \\
Reputation & 0.032 & 0.078 & 0.020 & 0.021 & 0.018 & 0.041 & 0.077 & 0.041 \\
Fin. Posi & 0.039 & 0.066 & 0.025 & 0.016 & 0.018 & 0.020 & 0.038 & 0.032 \\
\hline
\end{tabular}


Table 9 Original supplier matrix

\begin{tabular}{|c|c|c|c|c|c|c|}
\hline Criteria & Suppliers & Supplier 1 & Supplier 2 & Supplier 3 & Supplier 4 & Supplier 5 \\
\hline \multirow[t]{6}{*}{ Cost } & 1 & 1.000 & 5.000 & 7.000 & 9.000 & 0.111 \\
\hline & 2 & 0.200 & 1.000 & 3.000 & 7.000 & 0.200 \\
\hline & 3 & 0.143 & 0.333 & 1.000 & 5.000 & 0.200 \\
\hline & 4 & 0.111 & 0.143 & 0.200 & 1.000 & 0.111 \\
\hline & 5 & 9.000 & 5.000 & 5.000 & 9.000 & 1.000 \\
\hline & Net & 10.454 & 11.476 & 16.200 & 31.000 & 1.622 \\
\hline \multirow[t]{6}{*}{ Quality } & 1 & 1.000 & 7.000 & 9.000 & 5.000 & 3.000 \\
\hline & 2 & 0.143 & 1.000 & 5.000 & 0.333 & 0.200 \\
\hline & 3 & 0.111 & 0.200 & 1.000 & 0.200 & 0.143 \\
\hline & 4 & 0.200 & 3.000 & 5.000 & 1.000 & 0.333 \\
\hline & 5 & 0.333 & 5.000 & 7.000 & 3.000 & 1.000 \\
\hline & Net & 1.787 & 16.200 & 27.000 & 9.533 & 4.676 \\
\hline \multirow[t]{6}{*}{ Delivery } & 1 & 1.000 & 0.143 & 0.200 & 5.000 & 0.333 \\
\hline & 2 & 7.000 & 1.000 & 3.000 & 7.000 & 5.000 \\
\hline & 3 & 5.000 & 0.333 & 1.000 & 7.000 & 3.000 \\
\hline & 4 & 0.200 & 0.143 & 0.143 & 1.000 & 0.143 \\
\hline & 5 & 3.000 & 0.200 & 0.333 & 7.000 & 1.000 \\
\hline & Net & 16.200 & 1.819 & 4.676 & 27.000 & 9.476 \\
\hline \multirow[t]{6}{*}{ Warranty } & 1 & 1.000 & 8.000 & 8.000 & 6.000 & 7.000 \\
\hline & 2 & 0.125 & 1.000 & 1.000 & 7.000 & 8.000 \\
\hline & 3 & 0.125 & 1.000 & 1.000 & 7.000 & 8.000 \\
\hline & 4 & 0.167 & 0.143 & 0.143 & 1.000 & 0.167 \\
\hline & 5 & 0.143 & 0.125 & 0.125 & 6.000 & 1.000 \\
\hline & Net & 1.560 & 10.268 & 10.268 & 27.000 & 24.167 \\
\hline \multirow[t]{6}{*}{ Capacity } & 1 & 1.000 & 0.167 & 0.143 & 0.167 & 0.111 \\
\hline & 2 & 6.000 & 1.000 & 0.200 & 1.000 & 0.167 \\
\hline & 3 & 7.000 & 5.000 & 1.000 & 5.000 & 0.200 \\
\hline & 4 & 6.000 & 1.000 & 0.200 & 1.000 & 0.167 \\
\hline & 5 & 9.000 & 6.000 & 5.000 & 6.000 & 1.000 \\
\hline & Net & 29.000 & 13.167 & 6.543 & 13.167 & 1.645 \\
\hline \multirow[t]{6}{*}{ Reputation } & 1 & 1.000 & 1.000 & 5.000 & 1.000 & 5.000 \\
\hline & 2 & 1.000 & 1.000 & 5.000 & 1.000 & 5.000 \\
\hline & 3 & 0.200 & 0.200 & 1.000 & 0.200 & 1.000 \\
\hline & 4 & 1.000 & 1.000 & 5.000 & 1.000 & 5.000 \\
\hline & 5 & 0.200 & 0.200 & 1.000 & 0.200 & 1.000 \\
\hline & Net & 3.400 & 3.400 & 17.000 & 3.400 & 17.000 \\
\hline \multirow[t]{6}{*}{ Payment terms } & 1 & 1.000 & 0.200 & 7.000 & 6.000 & 4.000 \\
\hline & 2 & 5.000 & 1.000 & 9.000 & 7.000 & 5.000 \\
\hline & 3 & 0.143 & 0.111 & 1.000 & 0.200 & 0.167 \\
\hline & 4 & 0.167 & 0.143 & 5.000 & 1.000 & 0.333 \\
\hline & 5 & 0.250 & 0.200 & 6.000 & 3.000 & 1.000 \\
\hline & Net & 6.560 & 1.654 & 28.000 & 17.200 & 10.500 \\
\hline
\end{tabular}


Table 10 Adjusted supplier matrix

\begin{tabular}{|c|c|c|c|c|c|c|c|}
\hline Criteria & Suppliers & Supplier 1 & Supplier 2 & Supplier 3 & Supplier 4 & Supplier 5 & Weights \\
\hline \multirow[t]{5}{*}{ Cost } & 1 & 0.096 & 0.436 & 0.432 & 0.290 & 0.068 & 0.264 \\
\hline & 2 & 0.019 & 0.087 & 0.185 & 0.226 & 0.123 & 0.128 \\
\hline & 3 & 0.014 & 0.029 & 0.062 & 0.161 & 0.123 & 0.078 \\
\hline & 4 & 0.011 & 0.012 & 0.012 & 0.032 & 0.068 & 0.027 \\
\hline & 5 & 0.861 & 0.436 & 0.309 & 0.290 & 0.617 & 0.502 \\
\hline \multirow[t]{5}{*}{ Quality } & 1 & 0.560 & 0.432 & 0.333 & 0.524 & 0.642 & 0.498 \\
\hline & 2 & 0.080 & 0.062 & 0.185 & 0.035 & 0.043 & 0.081 \\
\hline & 3 & 0.062 & 0.012 & 0.037 & 0.021 & 0.031 & 0.033 \\
\hline & 4 & 0.112 & 0.185 & 0.185 & 0.105 & 0.071 & 0.132 \\
\hline & 5 & 0.186 & 0.309 & 0.259 & 0.315 & 0.214 & 0.257 \\
\hline \multirow[t]{5}{*}{ Delivery } & 1 & 0.062 & 0.079 & 0.043 & 0.185 & 0.035 & 0.081 \\
\hline & 2 & 0.432 & 0.550 & 0.642 & 0.259 & 0.528 & 0.482 \\
\hline & 3 & 0.309 & 0.183 & 0.214 & 0.259 & 0.317 & 0.256 \\
\hline & 4 & 0.012 & 0.079 & 0.031 & 0.037 & 0.015 & 0.035 \\
\hline & 5 & 0.185 & 0.110 & 0.071 & 0.259 & 0.106 & 0.146 \\
\hline \multirow[t]{5}{*}{ Warranty } & 1 & 0.641 & 0.779 & 0.779 & 0.222 & 0.290 & 0.542 \\
\hline & 2 & 0.080 & 0.097 & 0.097 & 0.259 & 0.331 & 0.173 \\
\hline & 3 & 0.080 & 0.097 & 0.097 & 0.259 & 0.331 & 0.173 \\
\hline & 4 & 0.107 & 0.014 & 0.014 & 0.037 & 0.007 & 0.036 \\
\hline & 5 & 0.092 & 0.012 & 0.012 & 0.222 & 0.041 & 0.076 \\
\hline \multirow[t]{5}{*}{ Capacity } & 1 & 0.034 & 0.013 & 0.022 & 0.013 & 0.067 & 0.030 \\
\hline & 2 & 0.207 & 0.076 & 0.031 & 0.076 & 0.102 & 0.098 \\
\hline & 3 & 0.241 & 0.380 & 0.153 & 0.380 & 0.122 & 0.255 \\
\hline & 4 & 0.207 & 0.076 & 0.031 & 0.076 & 0.102 & 0.098 \\
\hline & 5 & 0.310 & 0.456 & 0.764 & 0.456 & 0.608 & 0.519 \\
\hline \multirow[t]{5}{*}{ Reputation } & 1 & 0.294 & 0.294 & 0.294 & 0.294 & 0.294 & 0.294 \\
\hline & 2 & 0.294 & 0.294 & 0.294 & 0.294 & 0.294 & 0.294 \\
\hline & 3 & 0.059 & 0.059 & 0.059 & 0.059 & 0.059 & 0.059 \\
\hline & 4 & 0.294 & 0.294 & 0.294 & 0.294 & 0.294 & 0.294 \\
\hline & 5 & 0.059 & 0.059 & 0.059 & 0.059 & 0.059 & 0.059 \\
\hline \multirow[t]{5}{*}{ Payment terms } & 1 & 0.152 & 0.121 & 0.250 & 0.349 & 0.381 & 0.251 \\
\hline & 2 & 0.762 & 0.605 & 0.321 & 0.407 & 0.476 & 0.514 \\
\hline & 3 & 0.022 & 0.067 & 0.036 & 0.012 & 0.016 & 0.030 \\
\hline & 4 & 0.025 & 0.086 & 0.179 & 0.058 & 0.032 & 0.076 \\
\hline & 5 & 0.038 & 0.121 & 0.214 & 0.174 & 0.095 & 0.129 \\
\hline
\end{tabular}

Table 11 Overall AHP score

\begin{tabular}{llllccccc}
\hline Suppliers & Cost & Quality & Delivery & Warranty & Capacity & Reputation & Fin.Pos & Score \\
\hline Supplier 1 & 0.061 & 0.200 & 0.012 & 0.046 & 0.002 & 0.012 & 0.008 & 0.340 \\
Supplier 2 & 0.029 & 0.032 & 0.070 & 0.015 & 0.006 & 0.012 & 0.016 & 0.181 \\
Supplier 3 & 0.018 & 0.013 & 0.037 & 0.015 & 0.017 & 0.002 & 0.001 & 0.103 \\
Supplier 4 & 0.006 & 0.053 & 0.005 & 0.003 & 0.006 & 0.012 & 0.002 & 0.088 \\
Supplier 5 & 0.116 & 0.103 & 0.021 & 0.006 & 0.034 & 0.002 & 0.004 & 0.287 \\
\hline
\end{tabular}




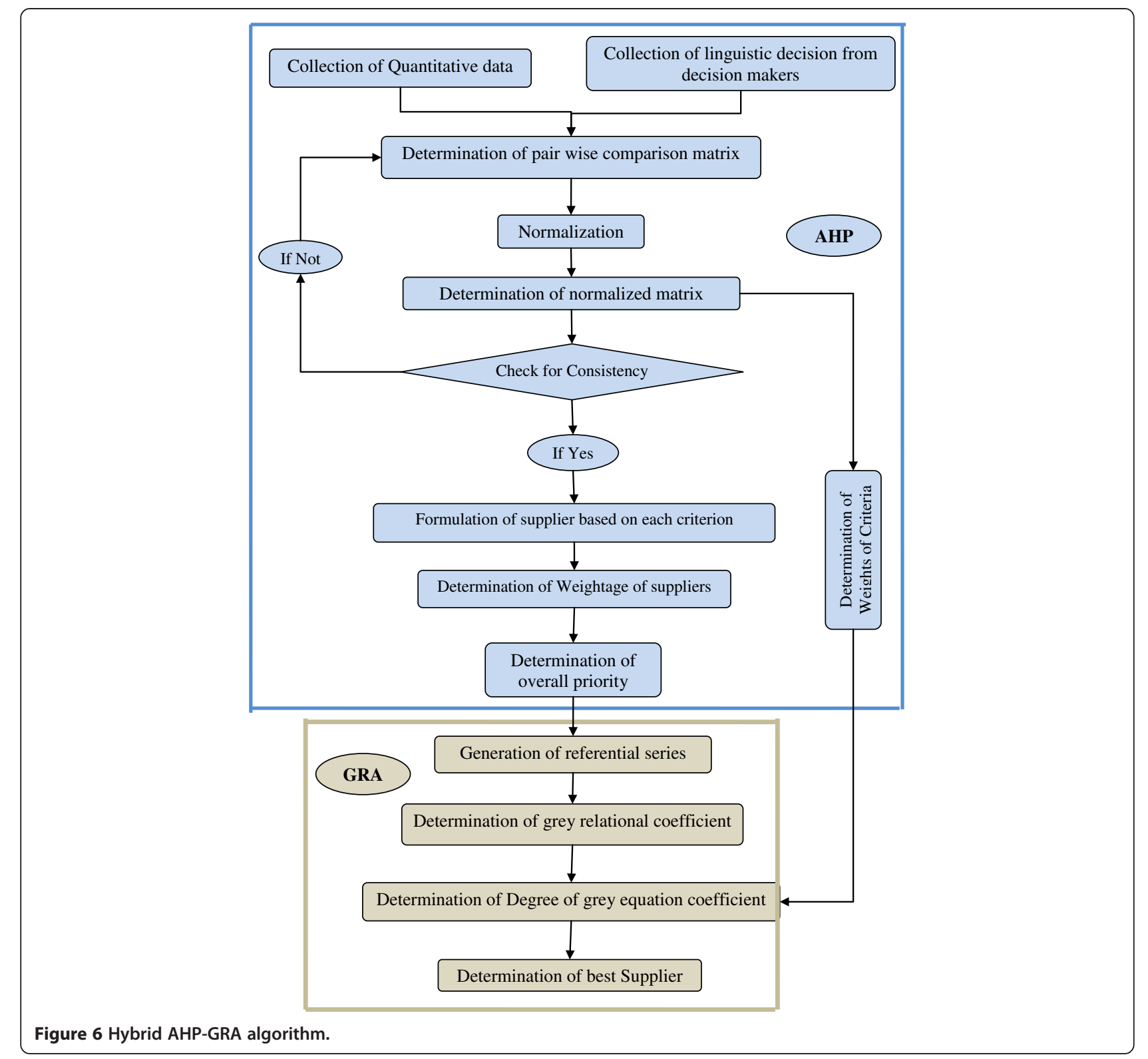

analysis the robustness of an optimal solution was tested and the sensitive variables were identified.

\section{Model 2: analytical hierarchy process (AHP)}

The Analytic Hierarchy Process (Thomas L. Saaty, 1980) is a powerful tool used to make decisions in situations when multiple and conflicting objectives/criteria are present. AHP helps capture both subjective and objective evaluation measures and provides a useful mechanism for checking the consistency of the evaluation measures and alternatives suggested by the team thus reducing bias in decision making. For the development of AHP models,

Table 12 Overall weights of criteria: hybrid AHP-GRA model

\begin{tabular}{|c|c|c|c|c|c|c|c|}
\hline Suppliers & Cost & Quality & Delivery & Warranty & Capacity & Reputation & Fin. position \\
\hline Supplier 1 & 0.061 & 0.200 & 0.012 & 0.046 & 0.002 & 0.012 & 0.008 \\
\hline Supplier 2 & 0.029 & 0.032 & 0.070 & 0.015 & 0.006 & 0.012 & 0.016 \\
\hline Supplier 3 & 0.018 & 0.013 & 0.037 & 0.015 & 0.017 & 0.002 & 0.001 \\
\hline Supplier 4 & 0.006 & 0.053 & 0.005 & 0.003 & 0.006 & 0.012 & 0.002 \\
\hline Supplier 5 & 0.116 & 0.103 & 0.021 & 0.006 & 0.034 & 0.002 & 0.004 \\
\hline
\end{tabular}


along with the criteria which were considered for the GRA based models, the following criteria such as performance assessment criteria (quality of the supplied materials), and business factors (reputation or brand image of the supplier and financial position of the supplier) were used. The advantage of the AHP model over the GRA based models is that the AHP model can be suitable to accommodate the qualitative criteria also. The AHP algorithm is shown in Figure 5.

In the AHP model, first a set of pair wise comparisons of the criteria which is known as criteria matrix (Table 5) was developed to prioritize the criteria based on a measurement scale (Table 6) defined by Saaty $(1990,2008)$. The criteria matrix was normalized and from the normalized matrix which is shown in Table 7, the weightage of each criterion was calculated.

Next the consistency of the proposed comparison matrix was checked. To check the consistency, the consistency ratio (CR) was calculated using the equation (10).

$$
\mathrm{CR}=\mathrm{CI} / \mathrm{RI}
$$

where $\mathrm{CI}=$ Consistency Index and RI $=$ Random indices.

$$
C I=\frac{\lambda_{\max }-m}{m-1}
$$

Where $^{\lambda \text { max }}=$ Max of B or m;

$$
B=\left(\frac{\frac{A_{1}}{w_{1}}+\frac{A_{2}}{w_{2}}+\frac{A_{3}}{w_{3}}+\ldots+\frac{A_{m}}{w_{m}}}{m}\right)
$$

where $m=$ Number of criteria and $A_{1}, A_{2} \cdot A_{m}$ are calculated using the equation (13).

$$
[\text { Xatt }][\text { Watt }]=[A]
$$

where $\mathrm{X}_{\text {att }}=$ criteria matrix;

$$
\mathrm{W}_{\text {att }}=\text { Weights matrix }=\left[\begin{array}{l}
W 1 \\
W 2 \\
W 3 \\
::: \\
:::: \\
W n
\end{array}\right] \text { and }[\mathrm{A}]=\left[\begin{array}{c}
A 1 \\
A 2 \\
A 3 \\
:::: \\
:::: \\
A m
\end{array}\right]
$$

Random indexes (RI) for various matrix sizes, $\mathrm{m}$, have been approximated by Saaty $(1990,2008)$ as shown in Table 8.

If the $\mathrm{CR}<0.10$ the decision maker's pairwise comparison matrix is acceptable (Saaty, 1990). For the proposed AHP model, the consistency ratio was calculated as 0.079 . Since this is less than 0.1 , this model is acceptable.

Then the weights of the suppliers based on each criterion were calculated by using the same procedure. The original supplier matrix and the normalized/adjusted supplier matrix are shown in Table 9 and Table 10. After that the overall matrix is calculated by multiplying the weightage
Table 13 Grey relational grade

\begin{tabular}{lcc}
\hline Suppliers & Grey equation coefficient & Value \\
\hline Supplier 1 & $\lceil 1$ & 0.800 \\
Supplier 2 & $\lceil 2$ & 0.485 \\
Supplier 3 & $\lceil 3$ & 0.487 \\
Supplier 4 & $\lceil 4$ & 0.636 \\
Supplier 5 & $\lceil 5$ & 0.492 \\
\hline
\end{tabular}

of each criterion with the weightage of the supplier for that criterion. From the overall matrix the higher priority will be selected as best alternative. Based on the total weight calculated the best supplier was calculated. Based on the outcomes of model application, the overall AHP score obtained for each supplier is given in Table 11.

The final score will be calculated by summing the weightage of all criteria for a particular supplier. From this Table 11, the supplier with higher score (Supplier 1) will be selected as best supplier.

\section{Hybrid model: AHP-GRA}

The major shortcoming of the GRA model is that it is difficult to incorporate the linguistic variable and sometimes there is not much difference between the degrees of the grey equation coefficient. Consequently it is the very critical situation for a decision maker to take a concrete decision. The limitations of the AHP are that it only works if the matrices are in the same mathematical form and other apparent drawback is the formation and usage of the scaling factors. To overcome these drawbacks, hybridization approach is proposed. In this hybrid approach AHP and GRA are combined together for the evaluation and selection of the best supplier. The algorithm for the hybrid AHP-GRA algorithm is shown in Figure 6. The solution methodology of this hybrid approach consists of two stages:

Stage 1: Determination of the weights of the attributes by using AHP.

Stage 2: Selection of supplier is done by grey relational grading using GRA.

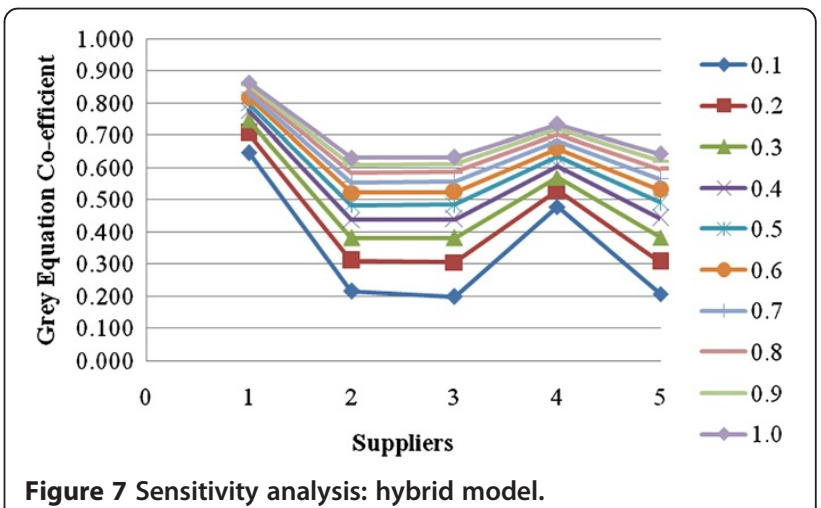




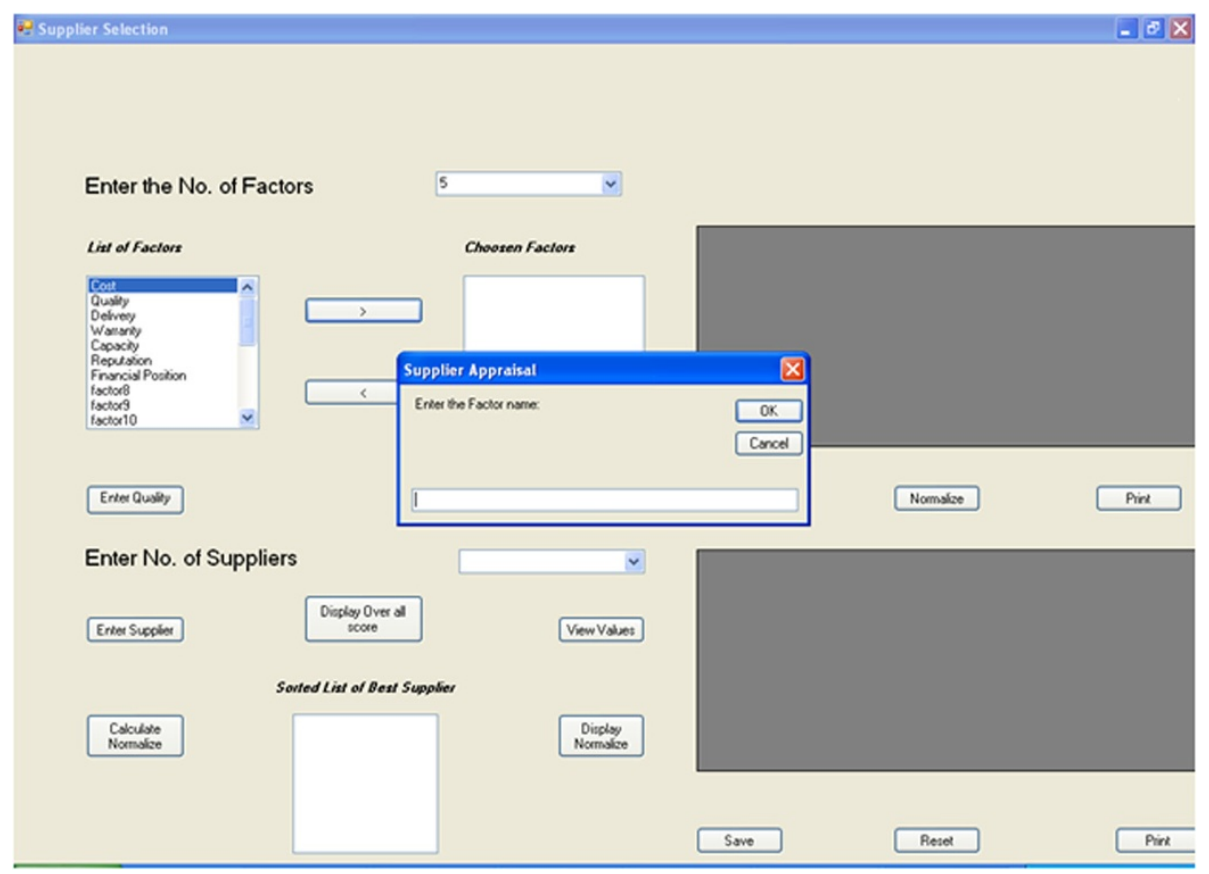

Figure 8 Snapshot of the developed DSS.

The weights for all criteria and the weights for alternatives were determined by AHP. The overall weights of criteria for the suppliers are shown in Table 12.

After the determination of weights using AHP, the ranking of suppliers is determined by GRA. The grey relational grade is determined and shown in Table 13. Finally the supplier with the higher grey relational grade (supplier 1) is selected as the best supplier.

The sensitivity of the grey relational grade was determined with the different distinguished coefficient $(\xi)$ which varies from 0.1 to 1.0, which is shown in Figure 7. From the Figure 7, it is understood that the ranking of supplier is highly sensitive with the change in coefficient.

\section{Systems integration and implementation}

Integration architecture configured all the subsystems design to assure easy and secure data sharing across subsystems. User integration enabled a system user to concentrate on the tasks to be accomplished and not on the specific details of the technological system being integrated. The integration can be done based on vertical, star and horizontal integration (Holsapple and Whinston, 1996). Vertical integration is the process of integrating subsystems according to their functionality. Star integration is a process of integration of the systems where each system is interconnected to each of the remaining subsystems. Horizontal integration is an integration method in which a specialized subsystem is dedicated to communication between other subsystems. In this proposed DSS all subsystems should be interconnected to perform the decision making process. Hence star integration technique was used in the DSS.

To prove the system's efficiency and practical application, the model based DSS for supplier selection and evaluation has been built. During the implementation, confirmation testing and validation have been properly carried out. Confirmation testing is the process of checking that the DSS has been developed according to the specifications, and that it is perfect and error-free. It evaluates the DSS for its completeness and accuracy. Set of confirmation tests such as interface integrity test, information content test and performance test were employed to determine the integrity of the individual sub system functions of a DSS (Turban et al., 2004). Interface integrity test first ensured the internal and external interfaces and then the integration of each module was incorporated into the DSS structure. Information content test was designed to reveal the errors associated with data base. The performance test was carried out to verify performance limits for the number of suppliers and number of criteria which were established during DSS design.

Validation is the determination of the correctness of the developed DSS with respect to the user's needs. Validation is generally accomplished by verifying each stage of the DSS by face validation and predictive validation. Face validation is the technique by which a system is evaluated by the feedback from several experts. Predictive validation makes use of case studies from either the literature or real world situations. In this work the 
developed DSS was validated by the feedback from the decision makers in the organization where the case study was conducted, the industrial experts who are in similar kind of industries and the subject experts from academic institutions.

In the implementation, the first entry of the DSS is the login menu. The users of the proposed DSS in the organization where the case study was performed are the purchase manager, purchase department staff specialists, staff assistant and system analyst. The duties and responsibilities of the staff specialists and staff assistant are collection and updation of supplier related data and the system analyst is maintaining the DSS. They can access the system through the intranet and can look through useful information stored in the database. Users must pass the authentication stage of security management. Without registration the users are not allowed to enter the system. Figure 8 shows the snapshot of the developed DSS.

The developed DSS has the flexibility of incorporate 23 criteria which were identified through literatures (Dickson, 1966). By using the DSS maximum upto 25 suppliers can be evaluated. The performance of the DSS is based on the number of criteria and the number of suppliers. When the matrix size is more DSS consume more time to evaluate which are not able to evaluate manually.

\section{Conclusion}

This paper presented a case study on solving the supplier selection problem in the Process industry through a model based decision support system that employs the analytical hierarchy process and grey relational analysis, a multicriteria methodology aiming towards providing comprehensive support to decision makers in a process industry for supplier selection. GRA model is an effective model where limited data are available. It can be used to evaluate the quantitative data. AHP model has the ability to handle problems which cannot be handled by mathematical models. It also used to solve the problem with qualitative and quantitative criteria in the same decision framework. AHP model can handle more number of criteria. The advantages of both GRA and AHP models are achieved in the hybrid model. The methodology has been implemented in an integrated DSS and provides the users with enhanced database management capabilities, several analysis options and reporting tools. The sensitivity analysis was also performed in order to improve the robustness of the results.

The proposed decision support system provides appropriate strategies to procurement operations that would meet the desired requirements and speed up the process of decision making in supplier selection process. This support system replaces the conventional methods employed by human decision makers with a systematic, consistent model based approach through the use of operations research models. The future scope will be the upgradation and expansion with knowledge based models which are developed by using computational intelligent techniques.

\section{Competing interests}

The authors declare that they have no competing interests.

\section{Authors' contributions}

Pitchipoo et al. developed a decision support system for the supplier selection process. It helps the decision makers to understand the specific information regarding the criteria used for the supplier selection process and various methodologies to be used by organizations for the evaluation and selection of suppliers. The proposed DSS will enable the purchasing officials to make the right sourcing decisions. All authors read and approved the final manuscript.

\section{Acknowledgements}

The authors wish to thank the Department of Mechanical Engineering of P.S. R Engineering College and Kalasalingam University for their kind permission to carry out the research.

\section{Author details}

${ }^{1}$ Department of Mechanical Engineering, P.S.R. Engineering College, Sivakasi626140, Tamil Nadu, India. ${ }^{2}$ Department of Mechanical Engineering,

Kalasalingam University, Krishnankoil - 626126, Tamil Nadu, India.

Received: 15 September 2012 Accepted: 22 August 2013

Published: 06 Sep 2013

\section{References}

Cebi F, Bayraktar D (2005) An integrated approach for supplier selection. Logist Inform Manage 16(16):395-400

Chakraborty PS, Majumder G, Sarkar B (2005) Performance evaluation of existing vendors using AHP. J Sci Ind Res 64(9):648-652

Chan FTS (2003) Interactive selection model for supplier selection process: an analytical hierarchy process approach. Int J Prod Res 41(15):3549-3579

Chan FTS, Chan HK, Ip RWL, Lau HCW (2007) A decision support system for supplier selection in the airline industry. P I Mech Eng B-J Eng 221(5):741-758

de Boer L, Labro E, Morlacchi P (2001) A review of methods supporting supplier selection. Eur J Purch Supply Manage 7(2):75-89

Deng JL (1989) Introduction to grey system. J Grey Sys 1(1):1-24

Dickson GW (1966) An analysis of vendor selection systems and decisions. J Purch 2(1):5-17

Efraim T, Aronson JE, Liang T-P (2004) Decision support systems and intelligent system. Prentice-Hall, NJ

Elanchezhian C, Vijaya Ramnath B, Kesavan R (2010) Vendor selection using analytical hierarchy process in supply chain management. J Engg Res Studies 1(1):118-127

Farzad Tahriri M, Osman R, Ali A, Yusuff RM, Esfandiary A (2008) An analytic hierarchy process approach for supplier evaluation and selection in a steel manufacturing company. J Ind Engg Manage 1(2):54-76

Henny van de Water, Heleen P van Peet (2006) A decision support model based on the analytic hierarchy process for the make or buy decision in manufacturing. J Purch Supply Manage 12(5):258-271

Holsapple CW, Whinston AB (1996) Decision support systems: A knowledge based approach. Thomson Learning Publishing, UK

Hou J, Daizhong S (2007) EJB-MVC oriented supplier selection system for mass customization. J Manuf Technol Manage 18(1):54-71

Hsu L-H, Ken M-L, Lein C-F (2008) The evaluation of the supplier's competencies for product innovation based on grey relational analysis -A Case for centrifugal pumps. J Grey Syst 11(1):1-10

Kumar S, Singh R (2008) An expert system for selection of piloting for sheet metal work on progressive die. J Sci Ind Res 67(10):774-779

Kumar S, Parashar N, Haleem A (2009) Analytical hierarchy process applied to vendor selection problem: Small scale, medium scale and large scale industries. Busi Intel J 2(2):355-362

Kumar V, Srinivasan S, Das S (2011) A multi-agent system for management of supplier selection process in a fuzzy supply chain. I J Comput Appl 23(6):31-37 
Lee D, Lee T, Lee S-k, Jeong O-r, Eom H, Lee S-g (2006) Bestchoice: a decision support system for supplier selection in e-marketplaces. Lect Notes Comput Sci 4055:198-208

Li G-D, Yamaguchi D, Nagai M (2008) A grey-based rough decision-making approach to supplier selection. I J Adv Manuf Technol 36(9-10):1032-1040

Ma J, Jie L, Zhang G (2010) Decider: A fuzzy multi-criteria group decision support system. Knowledge Base Syst 23(1):23-31

Martinez-Martinez JG (2007) Use of an alternative decision support system in vendor selection decisions. Int Met Buss J 3(2):1-14

Miah SJ, Huth M (2011) Cross-functional decision support systems for a supplier selection problem. I J Manage Decis Mak 11(3/4):217-230

Montazer GA, Saremi HQ, Ramezani M (2009) Design a new mixed expert decision aiding system using fuzzy ELECTRE III method for vendor selection. Expert Syst Appl 36(8):10837-10847

Moynihan GP, Puneet S, Fonseca DJ (2006) Development of a decision support system for procurement operations. I J Logist Syst Manage 2(1):1-18

Narasimahn R (1983) An analytical approach to supplier selection. J Purch Mat Manage 19(4):27-32

Noorul Haq A, Kannan G (2006) An integrated approach for selecting a vendor using grey relational analysis. I J Inform Techol Decis Mak 5(2):277-295

O'Brien JA, Marakas GM (2004) Management information systems: Managing information technology in the business enterprise. McGraw-Hill/ Irwin, Boston

Pitchipoo P, Venkumar P, Muthugurupackiam K, Rajakarunakaran S (2011) Modelling and development of decision model for supplier selection in process industry. I J Comput Aid Engg Technol 3(5/6):504-516

Pitchipoo P, Venkumar P, Rajakarunakaran S (2012) A distinct model for evaluation and selection of supplier for an electro plating industry. Int J Prod Res 50(16):4635-4648

Razmi J, Rafiei H, Hashemi M (2009) Designing a decision support system to evaluate and select suppliers using fuzzy analytic network process. Comput Ind Engg 57(4):1282-1290

Saaty TL (1980) The analytic hierarchy process: planning, priority setting, resource allocation. McGraw-Hill, New York

Saaty TL (1990) How to make a decision: The analytic hierarchy process. European J Oper Res 48(1):9-26

Saaty TL (2008) Decision making with the analytic hierarchy process. I J Ser Sci 1(1):83-98

Snijders C, Tazelaar F, Batenburg R (2003) Electronic decision support for procurement management: evidence on whether computers can make better procurement decisions. J Purch Supply Manage 9(5-6):191-198

Son YK (1991) A decision support system for factory automation: A case study. Int J Prod Res 29(7):1461-1473

Tsai C-H, Chang C-L, Chen L (2003) Applying grey relational analysis to the vendor evaluation model. Int J Comp Internet Manage 11(3):45-53

Tseng ML (2010) Using linguistic preferences and grey relational analysis to evaluate the environmental knowledge management capacity. Expert Syst Appl 37(1):70-81

Weber CA, Current JR, Benton WC (1991) Vendor selection criteria and methods. Eur J Oper Res 50(1):2-18

William H, Xiaowei X, Dey PK (2010) Multi-criteria decision making approaches for supplier evaluation and selection: A literature review. Eur J Oper Res 202 (1):16-24

Yang C-C, Chen B-S (2006) Supplier selection using combined analytical hierarchy process and grey relational analysis. J Manuf Technol Manage 17(7):926-941

\subsection{6/2251-712X-9-23}

Cite this article as: Pitchipoo et al: Modeling and development of a decision support system for supplier selection in the process industry. Journal of Industrial Engineering International 2013, 9:23 